\title{
Survival in Laparoscopic Surgery for Colon and Rectal Cancer
}

\section{Miguel Ángel Martínez-Alfonso ${ }^{1, *}$, Rafael Torres-Peña ${ }^{1}$, Javier Barreras-González ${ }^{1}$, Eduardo Alexis Manrique-González ${ }^{1}$, Jorge Gerardo Pereira-Fraga ${ }^{1}$, Rosalba Roque-González ${ }^{1}$, Raúl Jiménez-Ramos ${ }^{1}$, and Maricela Morera-Pérez ${ }^{2}$}

${ }^{1}$ Department of Surgery, National Center for Minimally Invasive Surgery (NCMIS), Cuba

${ }^{2}$ Department of Research, National Center for Minimally Invasive Surgery (NCMIS), Cuba

*Corresponding author: Miguel Ángel Martínez-Alfonso, Department of Surgery, National Center for Minimally Invasive Surgery (NCMIS), Havana, Cuba, Tel: 64953 33; E-mail: mangel@cce.sld.cu

Received: 12 Dec, 2019 | Accepted: 06 Jan, 2020 | Published: 13 Jan, 2020

Citation: Martínez-Alfonso MA, Torres-Peña R, Barreras-González J, Manrique-González EA, Pereira- Fraga JG, et al. (2020) Survival in Laparoscopic Surgery for Colon and Rectal Cancer. J Surg Open Access 6(1): dx.doi.org/10.16966/2470-0991.205

Copyright: (C) 2020 Martínez-Alfonso MA, et al. This is an open-access article distributed under the terms of the Creative Commons Attribution License, which permits unrestricted use, distribution, and reproduction in any medium, provided the original author and source are credited.

\begin{abstract}
Introduction: Colonic laparoscopic surgery has been performed since the early nineties of the past century. Despite its advantages: less postoperative pain, faster intestinal and respiratory functions recovery among others, its acceptance has not been the same as with other laparoscopic procedures. In oncologic surgery particularly, the main cause of non-acceptance has been the fear of not respecting oncologic criteria and reports on port-site metastases in the abdominal wall.
\end{abstract}

Objective: To determine patient survival after laparoscopic colorectal resections.

Material and Method: A descriptive, retrospective and longitudinal study was carried out at the National Center for Minimally Invasive Surgery from January 2005 to December 2015. The studied variables were age, gender, the reason for surgery, surgical technique, mortality, overall survival.

Results: When comparing survival curves according to tumor location, it was found that those patients with rectal tumors who underwent surgery had a significantly lower survival during complete follow-up than patients with tumors in the rest of the colon ( $p=0.032$ ). Significant differences were also found in survival curves regarding the stage disease; stage IV patients showed the worst survival during the follow-up of this series.

Conclusions: Survival in our study, with the limitations given by retrospective analysis, in patients who had surgery for colorectal cancer with minimally invasive techniques at five and ten years was $70.9 \%$ and $66.8 \%$ respectively, an appropriate rate and similar to that described in the scientific medical literature.

Keywords: Colorectal surgery; Overall survival; Colorectal cancer

\section{Introduction}

Laparoscopic colon resection has not had the same diffusion as other surgical techniques despite having been introduced in 1991 and reproducing the core advantages of being minimally invasive [1]. Disadvantages such as difficulty, long learning curve and increases in costs have been pointed out [2]. Although laparoscopy colorectal surgery has increased in the past years, the percentage of patients treated with this approach continues being low. In oncologic surgery particularly, the main cause of non-acceptance in the mid-90s was the fear of not respecting oncologic criteria and the reports on portsite metastases in the abdominal wall [3-7]. These techniques were introduced in our Center in 1995, both in benign as well as malignant conditions, the latter under a research protocol.

\section{Material and Methods}

A descriptive and retrospective study was carried out beginning with a prospective database of patients who underwent surgery due to a histologic diagnosis of colorectal cancer from January 2005 to
December 2015, at the National Center for Minimally Invasive Surgery (NCMIS). The studied variables were age, gender, preoperative diagnosis, surgical technique, stage and overall survival. Patients who underwent curative and palliative surgery were included in the study, while those with a tumor of $7 \mathrm{~cm}$ or more, as well as evidence of infiltration in adjacent organs diagnosed in the preoperative period, were excluded.

Staging and treatment were classified according to the National Comprehensive Cancer Network 2004 (NCCN) [8]. Surgeries were performed by the same surgical team, and informed consent was given by patients and relatives.

Results were analyzed using the statistical program SPSS 21. The data obtained from the nominal qualitative variables were summarized with absolute and relative frequencies, quantitative variables with descriptive statistics of central tendency and dispersion (average and standard deviation). Survival was estimated following the Kaplan-Meier method. 


\section{General Technical Aspects}

\section{Preoperative}

How to perform mechanical colon preparation a day before surgery is explained to all of the patients and antithrombotic prophylaxis is indicated.

The day of surgery elastic bandages are placed as prophylaxis for deep vein thrombosis and a prophylactic antibiotic is administered both at the perioperative stage. A urinary catheter is placed in the operating room. Orogastric intraoperative decompression is only utilized if required.

\section{Surgical technique}

The modified lithotomy position is used in every case, except in right resections where patients were placed at dorsal decubitus. Pneumoperitoneum is achieved with a veress needle sustaining an intra-abdominal pressure of 12 to $15 \mathrm{mmHg}$; three to five trocars were utilized.

In the right and transverse colectomies, anastomosis was performed extracorporeally with manually suture intestinal anastomosis or occasionally with a staple suture. In left colectomies and rectal surgeries, the ureter was systematically identified. The anastomosis was performed laparoscopically with a mechanic circular stapler of variable diameters. A leak test was performed. Abdominal drainage was not routinely placed. The specimen was removed protecting the abdominal wall to avoid implants.

\section{Results}

Between 2005 and 2015, 402 laparoscopic resections due to colorectal cancer were performed and the survival rate was studied.

The patient's age average was $66.6 \pm 12.4$ years, and there was a slight prevalence of females 210 (52.2\%) over males 192 (47.8\%). The average age was similar in both genders (females: 66.4 years, males: 66.9). Preoperative diagnoses are shown in table 1. Rectal cancer represented $43 \%$ of the preoperative diagnosis, followed in frequency by those located in the right colon and sigmoid. The most utilized surgical techniques were anterior resection of the rectum (Dixon), right hemicolectomy and sigmoidectomy, Abdominoperineal resection following Miles technique represented $7 \%$ of the procedures performed (Table 2).

Table 1: Patient Distribution by Operative Diagnosis. NCMIS 2005-2015.

\begin{tabular}{|l|c|c|}
\hline \multicolumn{1}{|c|}{ Preoperative Diagnosis } & No. & $\%$ \\
\hline Rectal Cancer & 173 & 43 \\
\hline Right Colon Cancer & 93 & 23.1 \\
\hline Sigmoid Cancer & 80 & 19.9 \\
\hline Left Colon Cancer & 31 & 7.7 \\
\hline Transverse Colon Cancer & 18 & 4.5 \\
\hline Multiple Familial Polyposis+Cancer & 3 & 0.7 \\
\hline Idiopathic Ulcerative Colitis+Cancer & 1 & 0.2 \\
\hline Right Colon and Rectal Cancer & 1 & 0.2 \\
\hline Sigmoid and Rectal Cancer & 1 & 0.2 \\
\hline Loco Regional Recurrence & 1 & 0.2 \\
\hline Total & 402 & 100 \\
\hline
\end{tabular}

In regards to staging based on the TNM classification, our study shows that $75.7 \%$ of the patients were in stages II and III and only $12.9 \%$ were in stage I. Staging was not possible in 17 cases because the biopsy report did not have all the required data (Table 3).

The maximum follow-up time was 10,7 years. From a total number of 402 patients who had surgery for colorectal cancer 89 died, representing $22.1 \%$ of the patients studied. There was an overall survival rate at 5 and 10 years of $70.9 \%$ and $66.8 \%$ respectively, as shown in table 4.

The research was restricted because of the inconvenience of not being able to determine the date of recurrences or metastases. That is the reason why we only present the distribution of absolute and relative frequencies of these variables without being able to determine survival free from progression or disease.

Locoregional recurrence was present in $2.5 \%$ of the patients (10 cases), and $14.4 \%$ (58 patients) had distant metastasis. Port site metastases in the abdominal wall occurred in two cases $(0.49 \%)$.

When comparing the survival curves by tumor location, it was found that those with rectal tumors had a significantly lower survival during follow-up than patients with tumors in other sites $(\mathrm{p}=0.032)$. Significant differences were also found in the survival curves based on the stage of the disease: stage IV patients showed the worst survival during the follow-up of the series $(\mathrm{p}=0.000)$ (Figures 1 and 2).

\section{Discussion}

Long-term oncologic results have been a controversial issue ever since minimally invasive techniques were implemented for colorectal

Table 2: Patient Distribution Based on Surgical Technique Performed. NCMIS 2005-2015.

\begin{tabular}{|l|c|c|}
\hline \multicolumn{1}{|c|}{ Surgical Technique } & No. & $\%$ \\
\hline Anterior Resection of the Rectum (Dixon) & 143 & 35.6 \\
\hline Right Hemicolectomy & 93 & 23.1 \\
\hline Sigmoidectomy & 68 & 16.9 \\
\hline Left Hemicolectomy & 41 & 10.2 \\
\hline Miles & 28 & 7 \\
\hline Transversectomy & 20 & 5 \\
\hline Coloanal Anastomosis & 5 & 1.2 \\
\hline Total Colectomy & 4 & 0.9 \\
\hline Total & 402 & 100 \\
\hline
\end{tabular}

Table 3: Patient Distribution following TNM Classification. NCMIS 2005-2015.

\begin{tabular}{|l|c|c|}
\hline \multicolumn{1}{|c|}{ TNM Classification } & No & $\%$ \\
\hline O & 3 & 0.7 \\
\hline I & 52 & 12.9 \\
\hline II A & 118 & 29.4 \\
\hline II B & 39 & 9.7 \\
\hline II C & 37 & 9.2 \\
\hline III A & 12 & 3.0 \\
\hline III B & 53 & 13.2 \\
\hline III C & 57 & 14.2 \\
\hline IV A & 11 & 2.7 \\
\hline IV B & 3 & 0.7 \\
\hline Unreliable Staging & 17 & 4.2 \\
\hline TOTAL & 402 & 100 \\
\hline
\end{tabular}


Table 4: Overall Survival by Type of Cancer and Stage. NCMIS 20052015.

\begin{tabular}{|l|c|c|}
\hline \multicolumn{1}{|c|}{ Survival Rate } & Five years & Ten years \\
\hline Overall & $70.9 \%$ & $66.8 \%$ \\
\hline Colon & $74.8 \%$ & $73.3 \%$ \\
\hline Rectum & $62.1 \%$ & $58.1 \%$ \\
\hline \multicolumn{1}{|c|}{ TNM } & \multicolumn{2}{|c|}{ Survival } \\
\hline Stage 0 & $100 \%$ & $100 \%$ \\
\hline Stage 1 & $78 \%$ & $65 \%$ \\
\hline Stage II & $83.1 \%$ & $79.5 \%$ \\
\hline Stage III & $54.7 \%$ & $52 \%$ \\
\hline Stage IV & $32.1 \%$ & $16 \%$ \\
\hline
\end{tabular}

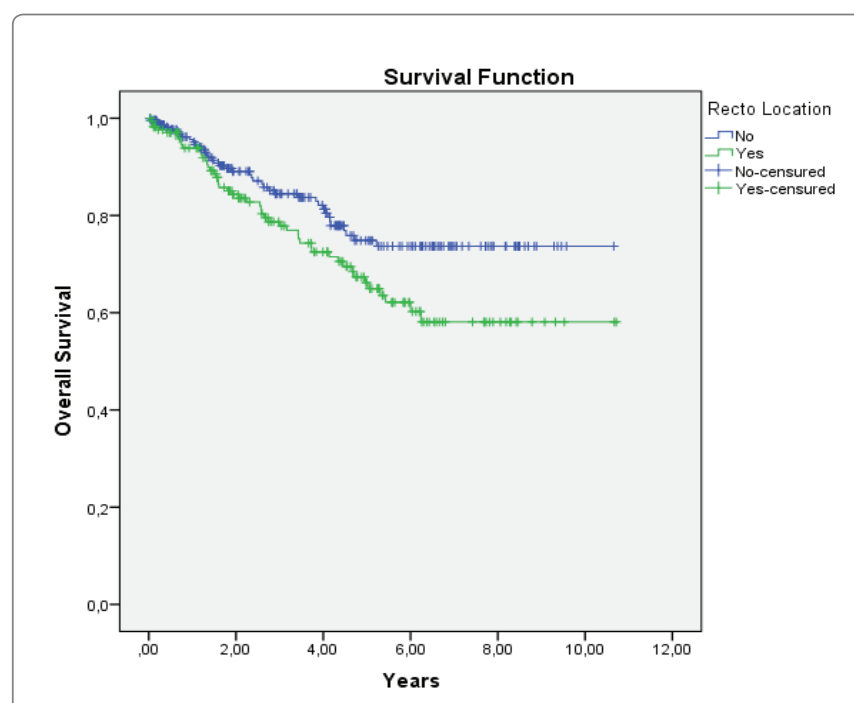

Figure 1: Overall Survival in Rectal Cancer.

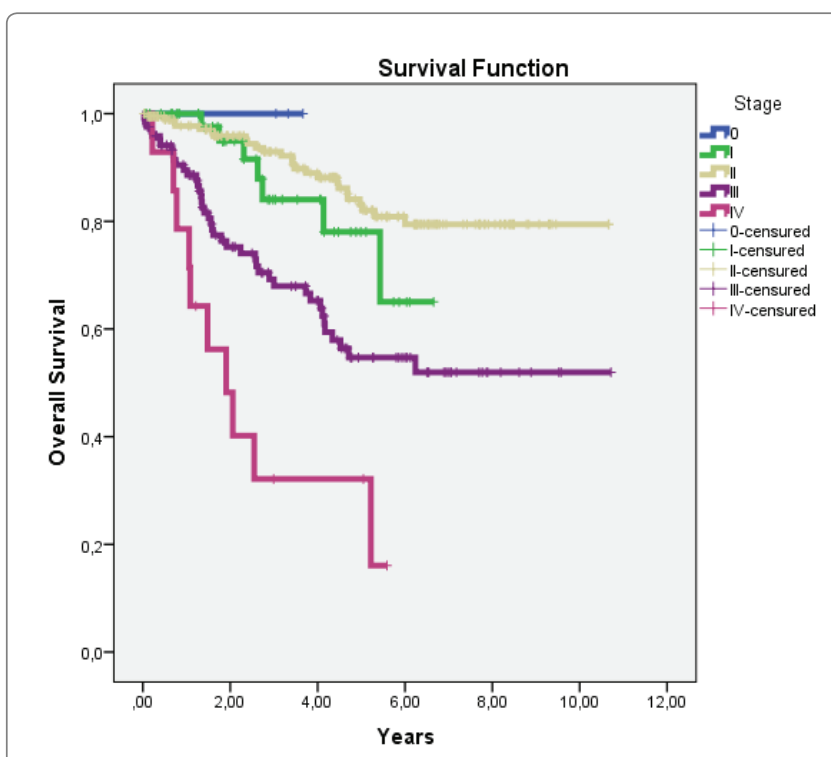

Figure 2: Overall Survival Regarding Staging. cancer. Although it was quickly demonstrated that the oncologic standards (resection margins and resected ganglia) were respected, the port site metastases reported at the level of the entry ports as well as mini incisions increased uncertainties and made many surgeons abandon this practice [4-7].

These criteria began to change and different societies began to implement laparoscopic surgery [9-11] with the results of the first prospective and multicenter studies which compared short and long term results of laparoscopic and conventional treatment of colon cancer presented at the Consensus Conference held in the EAES World Congress in Lisboa in 2004 [9]. In rectal cancer, laparoscopic techniques are more complex and there are different treatment methods determined by the location of the lesion and the use or not of radiotherapy, therefore it required more time to be accepted $[12,13]$.

The numbers of port-site metastases initially reported were alarming, but now in these first multicenter studies, they report less than $1 \%[7,8]$. In our series, there were two port site metastases at the level of the entry ports which represented $0.49 \%$, similar to European reports that informed $0.5 \%$ and $0.9 \%$ [14].

Mortality associated with colorectal cancer has been progressively diminishing, at least in developed countries [15]. This is probably due to the implementation of early detection programs and of a greater social awareness of the disease. Nevertheless, colorectal cancer is still one of the main causes of death.

In this series, the longest follow-up time was 10.7 years. Overall survival rate at five and ten years was $70.9 \%$ and $66.8 \%$ respectively. A worse prognosis was observed regarding tumor location in patients at five years with rectal cancer $(74.8 \%$ in colon cancer and $62.1 \%$ in rectal cancer) and at ten years $(73.7 \%$ in colon cancer and $58.1 \%$ in rectal cancer) similar to what is reported in the scientific medical literature [16]. This is probably related to the anatomical location of the rectum that prevents wider resections.

CLASIC [17], the multicenter study which included 794 patients in a comparative analysis of conventional colorectal surgery versus laparoscopic surgery reported survival of $78.3 \%$ and $82.7 \%$ at 5 years, respectively. In a more recent study of 161 patients operated on for cancer utilizing minimally invasive techniques, 92 in the colon and 69 in the rectum, overall survival at five years was $60.8 \%, 56.7 \%$ for colon cancer and $63.4 \%$ for rectal cancer [18].

A series of 108 patients who underwent conventional colorectal cancer surgery was published in Cuba in 2012; it reported $66.7 \%$ survival at five years [19].

Overall survival in this series at five years in colon surgery was $74.8 \%$, very similar to those published in a meta-analysis that includes COLOR and COST multicenter trials. When comparing the conventional and laparoscopic approaches in colon resections for cancer, they report this last group with $73.8 \%$ and $76.4 \%$ survival, respectively. In the same way, the local recurrence and distant metastasis report of $4 \%$ and $12.4 \%$ are similar to ours, $2.5 \%$ and $14.4 \%$, respectively [20]. An institutional study carried out in Italy which included 460 colon resections, 227 laparoscopic and 233 conventional, report a five-year survival of $83.1 \%$ and $68.5 \%$, respectively [21].

The numbers of overall survival vary more [18,22,23] regarding five-year survival in the treatment of rectal cancer, related to, among other aspects, the differences in staging, the neoadjuvant chemoradiotherapy protocols and surgical procedures (prior resections, abdominoperineal amputations, hand-assisted minimally invasive surgery, etc.). 
Table 5: Five-Year Survival of Colorectal Surgery for Cancer.

\begin{tabular}{|l|c|c|c|c|c|}
\hline \multicolumn{1}{|c|}{ Author } & Survival & Stage I & Stage II & Stage III & Stage IV \\
\hline $\begin{array}{l}\text { Akgun E, et al. [29] } \\
269 \text { patients }\end{array}$ & $62 \%$ & $91 \%$ & $82 \%$ & $51 \%$ & $4 \%$ \\
\hline $\begin{array}{l}\text { Kalcan S, et al. [18] } \\
161 \text { patients }\end{array}$ & $60.8 \%$ & $88.2 \%$ & $64.7 \%$ & $48.5 \%$ & $37 \%$ \\
\hline NCMIS 385 patients & $70.9 \%$ & $79.3 \%$ & $83.1 \%$ & $54.7 \%$ & $32.1 \%$ \\
\hline
\end{tabular}

When analyzing abdominal resections regarding Miles technique for rectal cancer, we observe that when comparing our first experiences (1995-2004) with this procedure performed on 27\% of the patients with cancer, there was a $16 \%$ decrease (28 Miles in 178 rectal cancers) in the period that covers this report due to a larger number of conservative techniques, that besides providing a higher life quality diminish the possibilities of local recurrence, the aforementioned a very debated issue nowadays [24-26].

In England, the analysis of national data between 1996 y 2004 demonstrated that the abdominoperineal resection rate significantly decreased from $29 \%$ to $21 \%$ [27].

There are few publications regarding survival at ten years after colorectal surgery. In 2016 Deijen CL, et al. [28] published a continuation of COLOR, the multicenter study, and reported $48.4 \%$ and $46.7 \%$, survival for colon cancer treated by laparoscopic and conventional approach respectively. Our ten-year survival in colon cancer $(73.7 \%)$ is similar to a series of 269 colectomies published by Akgun E, et al. [29] that reports $72.9 \%$ at ten years.

Staging is the strongest predictor of survival for patients with colorectal cancer considering that the prognosis of these patients mainly depends on the vertical engagement of the colonic wall and the condition of the ganglionic compromise.

In this study nearly $50 \%$ were Stage II patients (48.3\%), 30.4\% were in Stage III and only $17 \%$ were in the other stages. It calls our attention that in relation to overall survival depending on the stage of the disease, Stage I survival is lower than Stage II, the opposite of what was expected and reported by other series $[17,30]$ that like us, studied colon and rectal surgery. This could be related to the small Stage I sample in our series, among other factors table 5.

\section{Conclusions}

In our study, in spite of limitations given by retrospective analysis, the survival of patients with colorectal cancer who underwent surgery by minimally invasive techniques at five and ten years was $70.9 \%$ and $66.8 \%$ respectively, an appropriate rate and similar to that described in the scientific medical literature.

Survival curves in patients who had surgery for a rectal tumor were significantly lower during the total follow-up than in the patients with localized tumors in the colon. At five years it was $74.8 \%$ in those located in the colon and $62.1 \%$ in the rectum while at 10 years it was $73.3 \%$ and $58.1 \%$ respectively.

Significant differences were found in the survival curves regarding overall survival according to the stage of the disease.

\section{References}

1. Jacobs M, Verdeja JC, Goldstein HS (1991) Minimally invasive colon resection (laparoscopic colectomy). Surg Laparosc Endosc 1: 144150.
2. Pascual M, Salvans S, Pera M (2016) Laparoscopic colorectal surgery: Current status and implementation of the latest technological innovations. World J Gastroenterol 22: 704-717.

3. Küper MA, Eisner F, Königsrainer A, Glatzle J (2014) Laparoscopic surgery for benign and malign diseases of the digestive system: Indications, limitations, and evidence. World J Gastroenterol 20: 4883-4891.

4. Martinez J, Targarona EM, Balagué C, Pera M, Trias M (1995) Port site metastasis. An unresolved problem in laparoscopic surgery: A review. Int Surg 80: 315-321.

5. Berends FJ, Kazemier G, Bonjer HJ, Lange JF (1994) Subcutaneous metastases after laparoscopic colectomy. Lancet 344: 58.

6. Lacy AM, Delgado S, García-Valdecasas JC, Castells A, Piqué JM, et al. (1998) Port site metastases and recurrence after laparoscopic colectomy. A randomized trial. Surg Endosc 12: 1039-1042.

7. Vukasin P, Ortega AE, Greene FL, Steele GD, Simons AJ, et al. (1996) Wound recurrence following laparoscopic colon cancer resection. Results of the American Society of Colon and Rectal Surgeons Laparoscopic Registry. Dis Colon Rectum 39: S20-S23.

8. National Comprehensive Cancer Network (NCCN) (2020) NCCN Guidelines ${ }^{\circledR}$ \& Clinical Resources.

9. Veldkamp R, Gholghesaei M, Bonjer HJ, Meijer DW, Buunen M, et al. (2004) Laparoscopic resection of colon Cancer: consensus of the European Association of Endoscopic Surgery (EAES). Surg Endosc 18: 1163-1185.

10. Society of American Gastrointestinal Endoscopic Surgeons (SAGES) (2004) Laparoscopic colectomy for curable cancer. ASCRS.

11. Vogel JD, Eskicioglu C, Weiser MR, Feingold DL, Steele SR (2017) The American Society of Colon and Rectal Surgeons Clinical Practice Guidelines for the Treatment of Colon Cancer. Dis Colon Rectum 60: 999-1017.

12. Society of American Gastrointestinal and Endoscopic Surgeons (SAGES) (2012) Guidelines for Laparoscopic Resection of Curable Colon and Rectal Cancer.

13. Bonjer HJ, Deijen $\mathrm{CL}$, Abis GA, Cuesta MA, Van der Pas MH, et al. (2015) A Randomized Trial of Laparoscopic versus Open Surgery for Rectal Cancer. N Engl J Med 372: 1324-1332.

14. Yeo H, Niland J, Milne D, Veer AT, Bekaii-Saab T, et al. (2015) Incidence of Minimally Invasive Colorectal Cancer Surgery at National Comprehensive Cancer Network Centers. JNCI J Natl Cancer Inst 107: 1-8.

15. Ferlay J, Shin HR, Bray F, Forman D, Mathers C, et al. (2010) GLOBOCAN 2008: Cancer Incidence and Mortality Worldwide. IARC.

16. Jemal A, Bray F, Center MM, Ferlay J, Ward E, et al. (2011) Global cancer statistics. CA Cancer J Clin 61: 69-90.

17. Green BL, Marshall HC, Collinson F, Quirke P, Guillou P, et al. (2013) Long-term follow-up of the Medical Research Council CLASICC trial of conventional versus laparoscopically assisted resection in colorectal cancer. Br J Surg 100: 75-82.

18. Kalcan S, Sisik A, Basak F, Hasbahceci M, Kilic A, et al. (2018) Evaluating factors affecting survival in colon and rectum cancer: $A$ prospective cohort study with 161 patients. J Can Res Ther 14: 416420.

19. Guerra-Pérez E, Torres-Ajá L, Domínguez-Suárez J, Bernal-Muñoz J, Gastón-Avilés C (2012) Sobrevida a los cinco años en pacientes operados de neoplasia maligna de colon y recto. Revista Finlay 2: 11. 
20. Hai-Long B, Chen B, Zhou Y, Xiao-Ting W (2010) Five-year longterm outcomes of laparoscopic surgery for colon cancer. World J Gastroenterol 16: 4992-4997.

21. Cianchi F, Trallori G, Mallardi B, Macrì G, Biagini MR, et al. (2015) Survival after laparoscopic and open surgery for colon cancer: a comparative, single-institution study. BMC Surg 15: 33.

22. Ortega JA, Franco MB, Farfán MAP, Fernández MAP, Reyes Elizondo $C R$, et al. (2014) Resultados a largo plazo en el manejo quirúrgico del cáncer de recto: supervivencia a 5 años. Cir Gen 36: 225-231.

23. Rossi G, Vaccarezza H, Vaccaro C, Mentz R, Im V, et al. (2013) Tratamiento laparoscópico del cáncer de recto: resultados oncológicos a largo plazo. Rev Argent Cirug 105: 52-59.

24. Hussain A, Mahmood F, Torrance ADW, Clarke H, Howitt C, et al. (2018) Oncological outcomes of abdominoperineal resection for the treatment of low rectal cancer: A retrospective review of a single UK tertiary centre experience. Ann Med Surg (Lond) 34: 28-33.

25. Warschkow R, Ebinger SM, Brunner W, Schmied BM, Marti L (2017) Survival after Abdominoperineal and Sphincter-Preserving Resection in Nonmetastatic Rectal Cancer: A Population-Based Time-Trend and Propensity Score-Matched SEER Analysis. Gastroenterol Res Pract 2017: 6058907.

26. Omidvari $S$, Hamedi $S H$, Mohammadianpanah $M$, Razzaghi $S$, Mosalaei A, et al. (2013) Comparison of abdominoperineal resection and low anterior resection in lower and middle rectal cancer. J Egypt Natl Canc Inst 25: 151-160.

27. Tilney HS, Heriot AG, Purkayastha $S$, Antoniou A, Aylin $P$, et al. (2008) A national perspective on the decline of abdominoperineal resection for rectal cancer. Ann Surg 247: 77-84.

28. Deijen $\mathrm{CL}$, Vasmel JE, de Lange-de Klerk ESM, Cuesta MA, Coene PLO, et al. (2017) Ten-year outcomes of a randomised trial of laparoscopic versus open surgery for colon cancer. Surg Endosc 31: 2607-2615.

29. Akgun E, Caliskan C, Yoldas T, Karaca C, Karabulut B, et al. (2015) LongTerm Outcomes of Colon Cancer Patients Undergoing Standardized Technique Operation with Curative Intent. Int Surg 100: 1382-1395.

30. Oh HS, Chung HJ, Kim HK, Choi JS (2007) Differences in Overall Survival When Colorectal Cancer Patients are Stratified into New TNM Staging Strategy. Cancer Res Treat 39: 61-64. 